\title{
Multicomponent indices to predict survival in COPD
}

\author{
To the Editor:
}

The recent article by MARIN et al. [1] compared various multicomponent indices of chronic obstructive pulmonary disease (COPD) severity to see which best predicted survival and concluded ADO (age, dyspnoea and forced expiratory volume in $1 \mathrm{~s}$ (FEV1)) and BODE (body mass index, airflow obstruction, dyspnoea and exercise capacity) were the most valid. However, these were only the most valid of the indices they have considered. As committed researchers the authors should be looking to see how much better they can serve their patients with COPD and they have failed to consider refining the current indices in the light of available evidence. In these indices lung function is used as per cent of predicted which is a flawed method and has been shown not to be the best way of using lung function with respect to predicting survival $[2,3]$. I agree with the authors' statement that age, as for many other nonmodifiable factors, should have limited value in the clinical stratification of COPD. Per cent of predicted attempts to take age, sex and height into account, but leaves biases from each within the index. Young cystic fibrosis (CF) patients dying with airflow obstruction have FEV1 values that are just as low as middle-aged COPD patients dying of respiratory failure, so using per cent of predicted values will defeat survival analysis since the CF patient will have a much lower per cent of predicted value than the older COPD subject. Relating lung function values to predicted values is only of use when determining if the value is unexpected or abnormal. Severity of airflow obstruction, which relates to survival, is better defined by other means such as FEV1 divided by powers of height $[2,3]$ or by FEV1 quotient $[3,4]$. The authors should have considered using lung function in these ways within their multicomponent indices, since a preliminary study has indicated that the power of BODE to predict survival in COPD was dramatically increased by using FEV1 in this way [5]. Until researchers working in the field of COPD explore their data fully and challenge accepted norms we are likely to be limited by second best results from research studies and poorer treatments for our patients.

0

@ERSpublications

Lung function values expressed as \% predicted are not the most appropriate measure of airflow obstruction severity http://ow.ly/qxLdp

Martin R. Miller

Institute of Occupational and Environmental Medicine, University of Birmingham, Birmingham, UK.

Correspondence: M.R. Miller, Institute of Occupational and Environmental Medicine, University of Birmingham, Birmingham, B15 2TT, UK. E-mail: m.r.miller@bham.ac.uk

Received: Sept 032013 | Accepted: Sept 062013

Conflict of interest: None declared.

\section{References}

1 Marin JM, Alfageme I, Almagro P, et al. Multicomponent indices to predict survival in COPD: the COCOMICS study. Eur Respir J 2013; 42: 323-332.

2 Miller MR, Pedersen OF, Dirksen A. A new staging strategy for chronic obstructive pulmonary disease. Int J Chron Obstruct Pulmon Dis 2007; 2: 657-663.

3 Miller MR, Pedersen OF. New concepts for expressing forced expiratory volume in $1 \mathrm{~s}$ arising from survival analysis. Eur Respir J 2010; 35: 873-882.

4 Pedone C, Scarlata S, Scichilone N, et al. Alternative ways of expressing FEV1 and mortality in elderly people with and without COPD. Eur Respir J 2013; 41: 800-805.

5 Lawrence AD, Hildreth A, Taylor I, et al. A new multidimensional model for predicting mortality in COPD: body mass index and FEV1 quotient/MRC dyspnoea score (SID). Eur Respir J 2006; 28: Suppl. 50, 366s-367s. 